\title{
Histopathological occurrence and characterisation of calcium oxalate: a review
}

\author{
A. J. CHAPLIN
}

From the Histology Department, Gibson Laboratories, Radcliffe Infirmary, Oxford OX2 $6 H E, U K$

SUMMARY Oxalosis is the histological manifestation of a number of diverse clinicopathological states involving abnormalities of both endogenous and exogenous oxalate. Crystalline deposits of calcium oxalate, usually first detected by their birefringence, may be characterised by a combination of their physical and tinctorial properties.

'Oxalic acid is an example of a toxic substance that is consumed with impunity in small amounts in the daily food, yet when ingested in large amounts in pure form causes serious illness or death' (Jeghers and Murphy, 1945). Since that statement was made, a number of distinct clinical states involving the oxalate ion have been well defined, and it has been shown further that raised 'toxic' levels of oxalate may occur as a result of endogenous as well as exogenous processes. In such situations the solubility product of calcium oxalate may be exceeded, with consequent precipitation in tissues of this highly insoluble salt, a phenomenon known as oxalosis (Zarembski and Hodgkinson, 1967).

Calcium oxalate is a major constituent of most stones occurring in the urinary tract (Watts, 1973) and, as such, its presence has been unknowingly recognised since the time of Hippocrates (Smith, 1968), though only in the last century has it been identified histologically, initially in the thyroid (Zeiss, 1877) and kidney (Kobert and Küssner, 1879). In the light of subsequent knowledge, it is reasonable to assume that other reports of nonsilicous, acid soluble, doubly refractile material occurring histologically refer most probably to calcium oxalate, and indeed many of these reports have been confirmed in recent years. Much is now known of the metabolism of oxalic acid in health and disease, though organ selective deposition of calcium oxalate remains in many instances only poorly understood (Hodgkinson and Zarembski, 1968; Williams and Smith, 1972).

Despite these overall advances, more widespread knowledge of the histopathological occurrence of calcium oxalate is frequently scant, and few text-

Received for publication 28 March 1977 books of pathology make even passing reference to such crystals. The object of this article is to review the known examples of oxalosis and to discuss methods for the histological characterisation of the crystals.

(A) Histopathological occurrence of calcium oxalate

An initial division of the known states of oxalosi into 'hereditary' and 'acquired' may be made. It those occurring in the latter group that are more likely to be encountered in routine pathology. All types are summarised in Table 1.

\section{HEREDITARY OXALOSIS}

Primary hyperoxaluria is a general term for at least two rare genetic disorders of glyoxylate metabolism characterised by recurrent calcium oxalate nephrolithiasis, chronic renal failure, and usually death in uraemia at an early age. In $12 \%$ of cases symptoms occur before the age of 1 year, in $65 \%$ before the age of 5 years. About $80 \%$ die by the age of 20 , and

Table 1 Classification of main forms of oxalosis with underlying clinical states

\begin{tabular}{lll}
\hline 1 Hereditary & $\begin{array}{l}\text { Type I primary hyperoxaluria } \\
\text { Type II primary hyperoxaluria } \\
\text { ? Others }\end{array}$ Acquired \\
(a) Exogenous & $\begin{array}{l}\text { Oxalate poisoning } \\
\text { Ethylene glycol poisoning } \\
\text { Xylitol infusion } \\
\text { Methoxyflurane anaesthesia }\end{array}$ \\
(b) Enteric & $\begin{array}{l}\text { Hyperabsorption of normal dietary oxalate in } \\
\text { enteric disease }\end{array}$ \\
(c) Uraemic & $\begin{array}{l}\text { Hyperoxaluria in renal insufficiency } \\
\text { (d) Dystrophic }\end{array}$ & $\begin{array}{l}\text { Various. No apparent abnormality in body } \\
\text { oxalate levels }\end{array}$ \\
(e) Deficiency & ? Hyperoxaluria in vitamin deficiencies \\
\hline 00 & &
\end{tabular}


$90 \%$ of fatal cases display symptoms for less than 10 years (Williams and Smith, 1972).

In type I primary hyperoxaluria, a defective metabolism of glyoxylic acid leads to increased urinary oxalic and glycolic acids (glycolic acidosis), and in type II primary hyperoxaluria, a defect probably in hydroxypyruvate metabolism leads to increased urinary oxalic and glyceric acids (Lglyceric acidosis) (Williams and Smith, 1972). A form of hyperoxaluria occurring in adults differs from the classic type only in being rather less severe so that patients survive until later in life (Cochran et al., 1968). It seems possible also that there are further variants which are not yet fully characterised (Bourke and Costello, 1975).

Nephrocalcinosis and extrarenal oxalosis, which characterise the pathological findings, have been regarded by some as being pathognomonic of primary hyperoxaluria though this is not necessarily so. It has also been suggested that primary hyperoxaluria and generalised oxalosis are two distinct entities, the former being a manifestation of renal malfunction and the latter being the true metabolic disturbance comparable to cystinuria and cystinosis (Daniels et al., 1960). Most, however, agree with Archer et al. (1958) that both conditions are reflections of the same underlying defect, and that widespread oxalosis, the extreme manifestation of primary hyperoxaluria, is a tissue storage complication of excessive oxalate synthesis, comparable to urate deposition in tophaceous gout (Williams and Smith, 1972).

It has been pointed out that, strictly speaking, the primary hyperoxalurias are in fact secondary states resultant upon the primary genetic defect (Williams and Smith, 1968). Thus hereditary oxalosis seems an appropriate term for the occurrence of systemic crystalline deposits in these metabolic disorders.

The chief site of oxalate deposition in hereditary oxalosis is the kidney with up to $5 \%$ of the dry weight ascribable to calcium oxalate (Scowen et al., 1959). The crystals are found chiefly in tubular lumen, sometimes in interstitial tissue, but only rarely within glomeruli, and are often accompanied by pyelonephritic changes (Hockaday et al., 1964; Williams and Smith, 1968). Another important site of deposition is the myocardium, crystals occurring in both myocardial and conducting fibres. Such deposits may give rise to a variety of conduction defects and even to complete heart block (Stauffer, 1960; Deodhar et al., 1969; Coltart and Hudson, 1971).

Further deposits may be found in the media of arteries. This is the most common site of precipitation in many major organs and accounts for the majority of systemic deposits (Scowen et al., 1959). Arterial involvement may be associated with subintimal fibrosis, sometimes leading to ischaemic, even grangrenous lesions of the extremities (Boquist et al., 1973; Arbus and Sniderman, 1974). Further sites of predilection are the rete testis and bone, with crystals found within the Haversian systems of younger patients and the marrow of patients of any age (Williams and Smith, 1968). Less common areas of involvement include the central nervous system (Hughes, 1959), thymus, skeletal muscle and adipose tissue (Lindholm, 1965), synovial tissue (Mohr and Hey, 1969), lymph nodes (Klauwers et al., 1969), and skin (Jansen et al., 1974).

\section{ACQUIRED OXALOSIS}

This group includes cases of oxalosis which are more or less the direct result of the ingestion of substances which either contain the oxalate ion or which are readily metabolised to oxalate, and cases which may be attributed to substances quite unrelated to oxalic acid which are introduced for legitimate medical purposes but which undoubtedly give rise to toxic levels of oxalate by often obscure metabolic pathways. The frequency alone of enteric and uraemic oxalosis justifies their individual classification, while remaining examples may conveniently be grouped together as dystrophic oxalosis.

\section{(a) Exogenous oxalosis}

(i) Acute or chronic illness and even death may follow the ingestion of oxalic acid or one of the soluble oxalates (Jeghers and Murphy, 1945). The occurrence of such illness, particularly in children, as a result of eating rhubarb has been generally ascribed to oxalate toxicity (Crampton and Charlesworth, 1975) and, though most cases in England occurred in the first world war, when rhubarb leaves were recommended as a green vegetable substitute, there have been more recent instances (Tallqvist and Väänänen, 1960). Similarly, many grasses, such as sorrel, eaten by domestic grazing animals contain high levels of oxalate, leading to similar illness (James, 1972; Franco and Krinitz, 1973; Roughan and Slack, 1973). Renal dysfunction is a feature common to all these instances, and renal oxalosis has long been recognised as a further complication (Dunn et al., 1924). Thus excessive dietary intake of oxalate must always be considered as a possible causal agent of renal oxalate deposition.

(ii) Ethylene glycol, diethylene glycol, and propylene glycol (glycerin) are aliphatic straight chained saturated poly-alcohols used industrially as solvents and freezing-point depressants. Although glycerin is relatively innocuous, the increasing availability of the first two mentioned has been paralleled by an 
increase in reports of accidental ingestion, and ingestion either as an ethanol substitute or as a means of suicide (Friedman et al., 1962). It was the 'Massengill disaster' of 1937, in which over 75 people died after taking an elixir made up in $72 \%$ diethylene glycol, that forced recognition of the toxicity of the glycols (Geiling and Cannon, 1938). Soldiers drinking antifreeze as an alcohol substitute and suicidal ingestion result in similar illness and usually death (Pons and Custer, 1946; Friedman et al., 1962; Roscher, 1971). Renal and sometimes meningeal oxalosis are the characteristic pathological findings in many of these cases.

Only about $3 \%$ of ingested glycol is converted to oxalate, most of the remainder being metabolised to respiratory $\mathrm{CO}_{2}$. The intermediate metabolic products, glycolaldehyde and glycolic and glyoxylic acids, appear to be more toxic in large amounts than either the parent glycol or the end product oxalate, which is probably only a histologically significant phenomenon (Gessner et al., 1961; Bove, 1966).

(iii) Xylitol is a compound used parenterally as a carbohydrate energy source. Recently, a clinical syndrome associated with the use of xylitol has been described (Thomas et al., 1972). Acidosis is followed by deteriorating renal function and death. Oxalate crystals have been demonstrated in the kidney and brain of patients dying in this way (Evans et al., 1973; Schröder et al., 1974). More recent studies have suggested that patients with renal failure who are infused rapidly with large doses of xylitol are unable to excrete the large amounts of glycolic acid formed. This state could inhibit the reduction of glyoxylate to glycolate and so increase the simultaneous oxidation of glyoxylate to oxalate (Hauschildt et al., 1976). This may be due to the clinical state of the patient, or to a genetic abnormality of one of the enzymes involved in the metabolism of glyoxylate (Hauschildt and Watts, 1976).

(iv) Methoxyflurane (2,2-dichloro-1,1-fluoromethyl ether; Penthrane; MOF) is a volatile anaesthetic sometimes associated with postoperative renal complications including hyperoxaluria and intratubular oxalosis (Aufderheide, 1971). Most cases occur in the elderly, and the administration of tetracycline has been said to predispose to the complication (Kuzucu, 1970; Watts, 1973). The pathophysiological mechanism is not clear, and the nephrotoxicity has been ascribed to both possible metabolic products of MOF, ie, fluoride and oxalate (Mazze et al., 1971). Bullock et al. (1974) described a unique case of generalised oxalosis in a patient dying in renal failure some three and a half years after MOF anaesthesia. Oxalate deposits were found in the kidney, bronchus, epididymus, peri- cardium, thyroid, and retinal pigment epithelium. Bergstrand et al. (1972) described an interesting series of cases of oxalate deposition in kidneys transplanted under MOF anaesthesia and suggested that ischaemia and tubular necrosis may particularly predispose to oxalosis after MOF anaesthesia. A recent isolated report has implicated halothane anaesthesia in a similar way (Cotton et al., 1976).

\section{(b) Enteric oxalosis}

There is much interest currently in an acquired form of hyperoxaluria related to intestinal disease. Dowling et al. (1971) first reported hyperoxaluria and oxalate urolithiasis in patients with extensive small bowel disease or undergoing resection of the small bowel. Later, diverticular disease, pancreatic insufficiency, and coeliac sprue were shown to give rise to a similar clinical state (Gelfand and Taranto, 1973; Saunders et al., 1975). Children are equally as prone as adults (Valman et al., 1974), and in children, at least, hepatic dysfunction may be associated with this 'enteric hyperoxaluria' (McCollum et al., 1974).

Since preformed crystal aggregates are essential for the genesis and growth of calculi (Vermeulen and Lyon, 1968) it is not surprising that in these cases with a high tendency to urolithiasis, oxalate have been demonstrated in renal material (Fig. 1, (Cryer et al., 1975; Vainder and Kelly, 1976). More widespread oxalosis has been described in such patients coming to necropsy (Lewis et al., 1974; Beppu et al., 1975).

These patients generally have an excessive excretion of bile salts in faeces, and it was originally thought that bacterial degradation of glycocholate liberates glycine which is oxidatively deaminated to oxalate (Watts, 1973). It has been shown subsequently that the hyperoxaluria is in fact due to an increase in the uptake of normal dietary oxalate, possibly due to the excessive colonic luminal concentration of bile salts and long chain fatty acids (Earnest et al., 1974; Saunders et al., 1975).

There has been mild controversy over the nature of certain spheroidal crystals found in renal tubules in cases of severe hepatic disturbances. These have been called 'leucine like' by Allen (1962) and calcium oxalate by Fanger and Esparza (1964). Allen (1976) doubts the validity of the latter, chiefly on a morphological basis, though in-vitro studies have shown that calcium oxalate will crystallise in an identical spheroidal form as well as the more common sheaf-like forms (Chaplin and Grace, 1975). Johnson and Pani (1962) identified birefringent renal crystals in severe liver disease as calcium oxalate rather than amino acids. In view of these facts, and the general pattern of enteric 


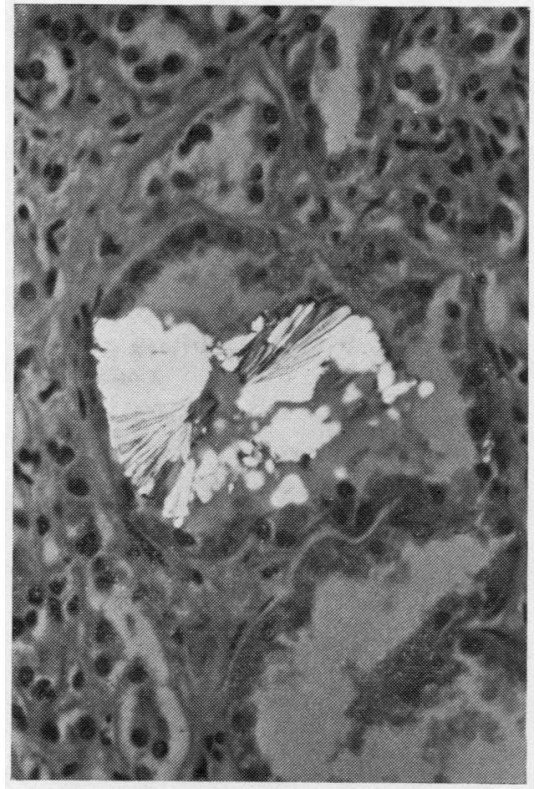

Fig. 1 Enteric oxalosis in the kidney of a 64-year-old man who died with pancreatitis. Haematoxylin and eosin $\times 285$ in semipolarised light.

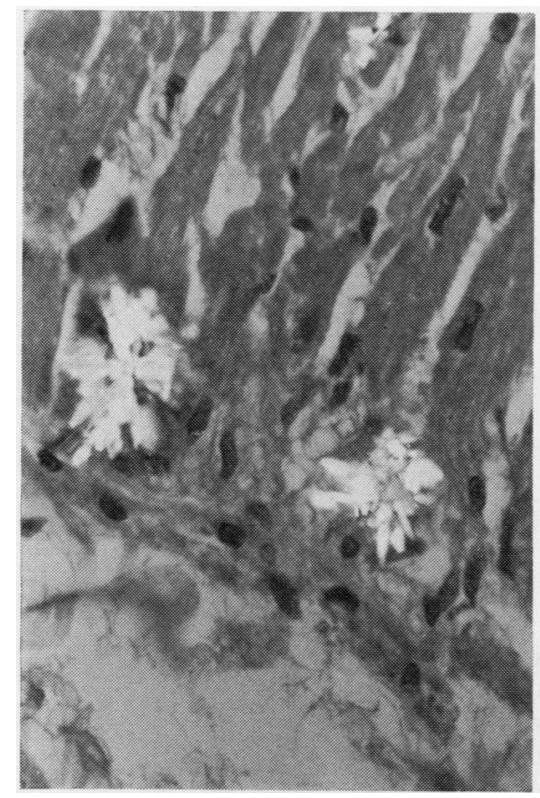

Fig. 2 Uraemic oxalosis in the myocardium of a 48-year-old woman who died in chronic renal failure. $H$ and $E \times 390$ in semipolarised light. oxalosis, it seems likely that these crystals do represent calcium oxalate, possibly in atypical form or with other coexistent trace components.

\section{(c) Uraemic oxalosis}

Crystals of calcium oxalate are found quite frequently in the kidneys apart from the instances already mentioned. Macaluso and Berg (1959) were probably the first to make a deliberate study of the incidence of such crystals, finding them in 25 out of 54 kidneys involved by renal disease. All their cases with severe deposition had been anuric or oliguric for prolonged periods. The occurrence of crystals was highest in acute tubular necrosis, while coexistent pancreatic or hepatic lesions were frequent. Bennett and Rosenblum (1961) described renal crystals in 34 out of 50 cases with uraemia. Bennington et al. (1964) found renal oxalate deposits in $6.4 \%$ of a series of consecutive necropsies but could find no statistical correlation between renal oxalosis and renal disease. They noted a significant incidence of concurrent neoplasia but no particular relation to hepatic disorders. A similar percentage, $6.2 \%$, was found in a further series of necropsies by Fanger and Esparza (1964), who noted an association with uraemia, often of pre-renal origin, with hepatic disorders and shock. Yasue (1969b) also found a higher incidence of renal oxalosis in renal and hepatic disease and neoplasia, while Salyer and Keren (1973) described renal deposits in over $70 \%$ of patients with renal insufficiency.

It seems probable that many of these cases are instances of enteric oxalosis. There is no doubt that oxalosis in association with renal insufficiency and uraemia is frequent and often extensive. It appears also that the incidence and severity of the oxalosis is related largely to the duration of the renal insufficiency (Salyer and Keren, 1973). Renal excretion is the only outlet for endogenous oxalate in man (Hockaday et al., 1964), and it has been shown that plasma oxalate levels run parallel to plasma urea levels in cases of renal failure (Zarembski et al., 1966).

Although the kidney is the most obvious precipitation site in uraemic oxalosis, deposits have also been described in bone (Milgram and Salyer, 1974; Kinnett and Bullough, 1976) and, perhaps more significantly, in the myocardium (Fig. 2). In the latter, oxalate crystals have been found in between 10 and $16 \%$ of patients who died with uraemia (Bennett and Rosenblum, 1961 ; Salyer and Hutchins, 1974). As with hereditary oxalosis, cardiac conduction defects have been manifest in some of these patients (Salyer and Hutchins, 1974). This emphasises that myocardial oxalosis must be regarded as a potential complication of renal failure since it is 
apparent that oxalate induced myocardial abnormalities may contribute to congestive heart failure and conduction abnormalities in uraemic patients.

\section{(d) Dystrophic oxalosis}

Most instances of oxalosis discussed so far are comparable to so-called 'metastatic calcification' in that they occur in normal tissues as a result largely of an hyperoxalaemia. Metastatic calcification occurs similarly as the result of hypercalcaemia, whereas dystrophic calcification occurs with no apparent disturbance of calcium metabolism in altered, damaged, degenerating or necrotic tissues.

There are instances of oxalosis which may also be termed dystrophic in that they, too, occur in altered tissues without apparent disturbance of oxalate metabolism.

(i) There are numerous reports of oxalosis in ocular tissue. Flocks et al. (1955) described lenticular crystals in $18 \%$ of 138 cases of glaucoma associated with hypermature cataract. There have been various instances of oxalate found subretinally or in the outermost layers of degenerate retinas, usually associated with old detachments, often in traumatised eyes (Cogan et al., 1958; Zimmerman and Johnson, 1958; Garner, 1974) or associated with diabetes (Friedman and Charles, 1974). Garner (1974) suggested that intraocular ascorbic acid could be the immediate oxalate precursor in these situations while Jensen (1975), finding oxalate actually within the retinal pigment epithelium, suggested that the latter may be intimately involved in the pathogenesis of ocular oxalosis.

(ii) Although arteries are sites of predilection for oxalosis in the hereditary states, there is only a single report not associated with primary hyperoxaluria. Glynn (1940) described oxalate crystals in the media of the left middle cerebral artery distal to a fatal ruptured aneurysm. An equally enigmatic and also isolated case of oxalosis is that described by Dyke et al. (1971), who found massive oxalate deposits in a benign mixed tumour of the parotid.

(ii) A rather more straightforward oxalosis is that occurring in association with aspergillosis (Fig. 3). Nime and Hutchins (1973) demonstrated oxalate crystals in areas of necrosis adjacent to mycelia in 11 out of 18 cases of aspergillosis and suggested that this phenomenon may be an in-vivo characteristic of Aspergillus niger, though all strains of Aspergillus are known to produce oxalic acid (Raper and Fennell, 1965). In a further example, a fatal pulmonary haemorrhage was ascribed to tissue damage and necrosis caused by the oxalosis (Kurrein et al., 1975).

(iv) Oxalates have been identified in giant cells in various granulomatous lesions, such as skin granuloma, and in tuberculous or chronic granulomatous

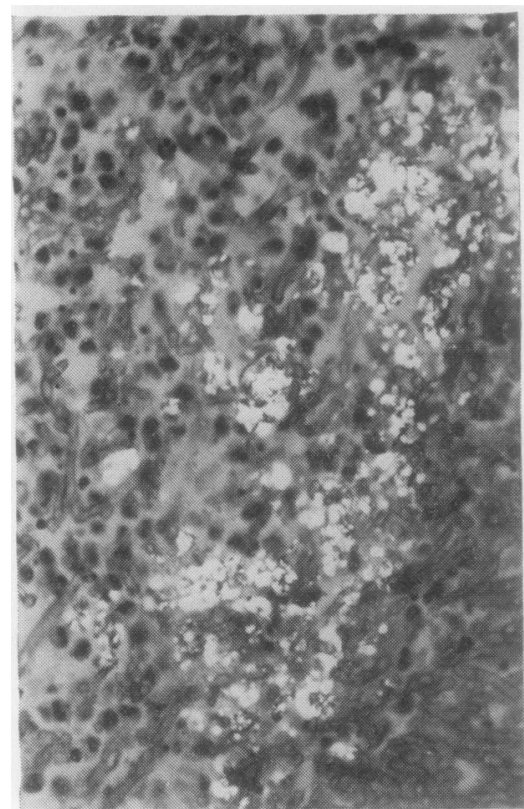

Fig. 3 Dystrophic oxalosis in a pulmonary Aspergillus abscess in a 70-year-old woman who died of pneumonia. $H$ and $E \times 300$ in semipolarised light.

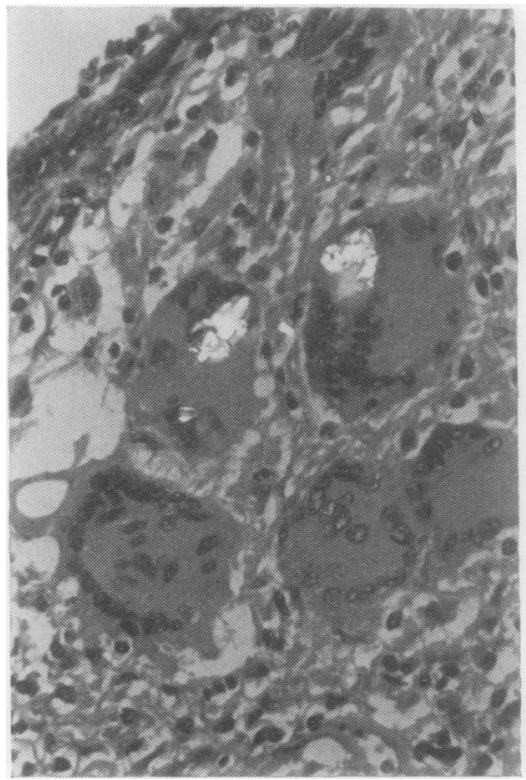

Fig. 4 Dystrophic oxalosis in giant cells in the Fallopian tube of a 47-year-old woman with tuberculous salpingitis. $H$ and $E \times 300$ in semipolarised light. 
salpingitis (Fig. 4) (Johnson and Pani, 1962). In sarcoid granuloma, calcium oxalate may be found, often associated with Schaumann bodies, in giant cells (Doyle et al., 1973). In a very limited subjective study, oxalates in sarcoid appeared to occur far more frequently in pulmonary lesions than in other sites (Fig. 5) (Chaplin, 1976a). It should be mentioned that sarcoid is sometimes accompanied by a modest hyperoxaluria of obscure significance (Dempsey et al., 1960). Although oxalates in these sites are considered the result rather than the cause of the inflammatory process (Johnson and Pani, 1962), it has been shown that oxalates can cause foreign body giant cell granuloma when injected directly into muscle (Gross, 1955). Many investigators have noted foreign body reaction to oxalate crystals in true pathological situations (see below).

(v) Gross (1955) found oxalate deposits in all 14 cases of diverse granulomatous thyroiditis but in only four out of 29 non-granulomatous thyroid diseases. The crystals occurred in the intra-acinar colloid as well as in central or peripheral granulomata and occasional giant cells. Any explanation of oxalosis in this situation is complicated by the frequent occurrence of oxalate crystals in normal thyroids (Fig. 6). Richter (1940) found deposits in $37 \%$ of a series of thyroids and noted a higher incidence in older patients and in the more normal thyroids of any given age group. The studies of Sanderson-Damberg (1910) suggest that dietary or other environmental factors may be significant. Richter and McCarty (1954) suggested that changes in the state of the colloid with increasing age may influence not only the formation but also the morphology of oxalate deposits. Lewis et al. (1974) found three distinct forms of calcium oxalate in one thyroid, and emphasised the possibility of extremely localised differences in concentration gradients or localised biochemical anomalies produced by disturbed oxalate metabolism in the same organ. These findings are borne out by in-vitro findings which have demonstrated that oxalate crystallisation is different in a colloidal than an aqueous environment, and is influenced also by other normally or pathologically occurring substances (Sutor, 1969; Bisaillon and Tawashi, 1975; Chaplin and Grace, 1975).

\section{(e) Deficiency oxalosis}

Pyridoxine is a co-factor in glyoxylate metabolism, and, in experimental animals, a deficiency of pyridoxine leads to hyperoxaluria and oxalosis (Gershoff et al., 1959). Although in man an induced deficiency leads to progressive hyperoxaluria, there is currently no evidence to implicate oxalosis (Faber et al., 1963). Thiamine pyrophosphate is also

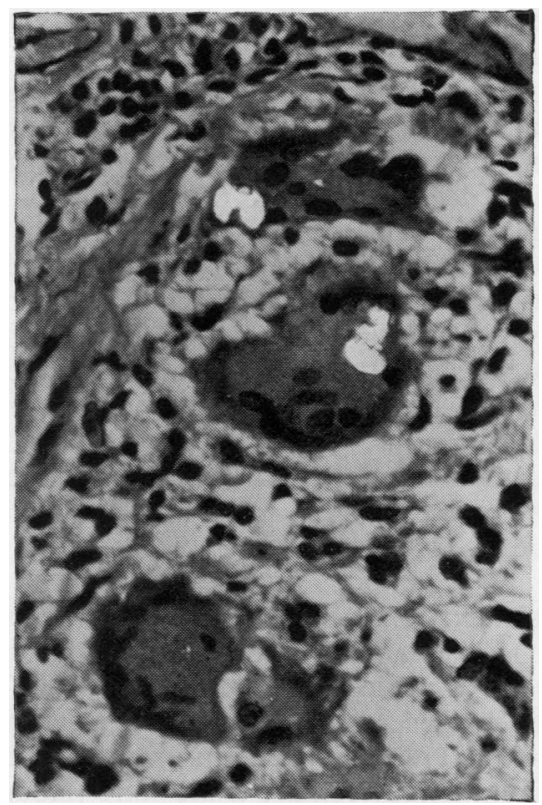

Fig. 5 Dystrophic oxalosis in giant cells in a pulmonary sarcoid lesion from a 57-year-old woman. $H$ and $E$ $\times 390$ in semipolarised light.

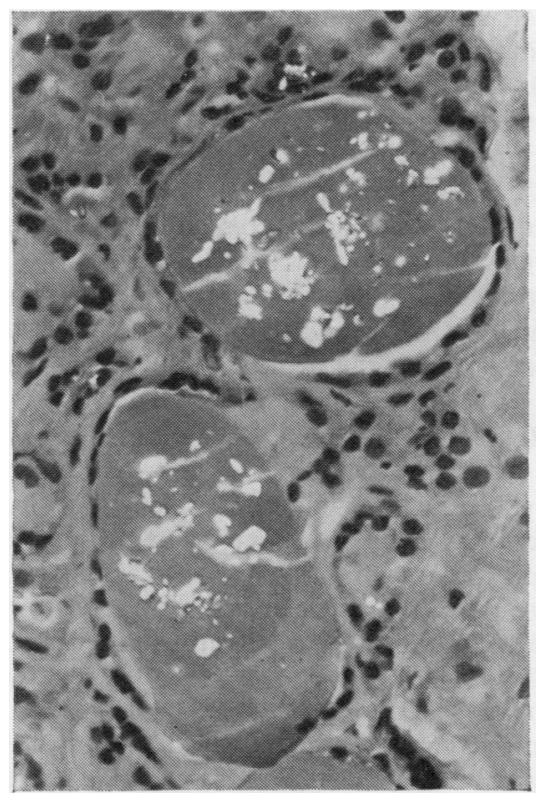

Fig. 6 Dystrophic oxalosis in the thyroid of an 84-year-old woman who died of a CVA. H and $E \times 285$ in semipolarised light. 
essential in the normal metabolism of glyoxylate and, in theory, a thiamine deficiency could lead to increased formation and excretion of oxalate and glycolate (Williams and Smith, 1968). There have been no reports of this, and in a recent study of thiamine deficiency cases there was no greater incidence of renal oxalosis than in control groups (Salyer and Salyer, 1974). It is assumed that the severity of the deficiency required for hyperoxaluria to develop is greater than that required for the clinical manifestations. Recently, hyperoxaluria associated with raised vitamin $\mathrm{C}$ intake has been described (Briggs, 1976; Harris, 1976). Each of these states involving vitamin abnormalities must always be considered in oxalosis of otherwise obscure pathogenesis.

\section{TISSUE REACTION TO OXALATE DEPOSITS}

Reference has already been made to the fact that oxalates may cause some reaction in tissues. Calcium oxalate is generally extremely inert, but tissue changes are presumably due to its local dissociation and liberation of toxic oxalate ions (Hodgkinson and Zarembski, 1968). It has indeed been shown that, despite the low solubility of calcium oxalate, oxalate deposition in tissues is not necessarily an irreversible process (Bergstrand et al., 1972).

A fibroblastic reaction around crystals as well as frank fibrosis has been observed in renal tissue (Bennett and Rosenblum, 1961; Boquist et al., 1973) while in the myocardium slight chronic inflammation, fibrosis, and focal necrosis have all been seen (Bennett and Rosenblum, 1961; Koten et al., 1965; Salyer and Keren, 1973; Salyer and Hutchins, 1974). Apart from the instances already mentioned, foreign body reactions to oxalate crystals have been described in bone marrow (Deodhar et al., 1969; Milgram and Salyer, 1974) and ocular tissue (Jensen, 1975) while Hughes (1959) described rosettes of microglia around crystals in brain.

\section{(B) Histological characterisation of calcium oxalate}

Various sophisticated techniques such as $x$-ray diffraction, electron microprobe, and chromatography have all been used to identify calcium oxalate derived from histological material (Bennett and Rosenblum, 1961; Bennington et al., 1964; Evans et al., 1973). Facilities for such techniques are not always readily available, while the random orientation and fragmentation of the crystals create difficulties in their application. Thus more simple methods are preferable and indeed are quite adequate for the histological characterisation of oxalates. The more pertinent of these, summarised in Table 2 , serve to distinguish calcium oxalate from a wide variety of potentially confusing substances of both endogenous and exogenous origin (Wolman, 1975).

Table 2 Summary of histological properties of calcium oxalate

\begin{tabular}{ll}
\hline Physiochemical properties & Positive histochemical reactions \\
\hline Birefringence & $\begin{array}{c}\text { Yasue's silver nitrate-rubeanic acid } \\
\text { method } \\
\text { von Kossa's silver nitrate method }\end{array}$ \\
$\begin{array}{l}\text { Insolubility in acetic acid } \\
\begin{array}{l}\text { Solubility in mineral acids } \\
\text { Conversion to CaCO, by } \\
\text { microincineration }\end{array}\end{array}$ & $\begin{array}{l}\text { Pizzolato's mercurous nitrate method } \\
\text { Naphthalhydroxamic acid method }\end{array}$ \\
\hline
\end{tabular}

1 OPTICAL PROPERTIES

The identification of crystals by their optical 10 properties is well known, and detailed descriptions of the theory and practice of quantitative polarisation microscopy are available (Hartshorne and $\frac{9}{3}$ Stuart, 1970). In such studies, various optical $\vec{C}$ characteristics are determined using whole crystals whose orientation is known and controlled, whereas in histological studies the crystals are randomly orientated and often fragmented, creating difficulties in interpretation. However, at least four optical properties may be useful to the present problem.

\section{(a) Habit}

In histological material, calcium oxalate occurs many forms, though basically there are three major forms-rosettes of rods, dipyramids or diamondshaped crystals, and large overlapping plates. It is not uncommon for all major forms to occur simultaneously in a single organ (Lewis et al., 1974).

\section{(b) Birefringence}

Crystals of calcium oxalate may be readily detected by virtue of their positive form birefringence in polarised light. Most crystals display white or higher first-order polarisation colours, while the plates may show second or even third order colours (Peterson and Kuhn, 1965).

\section{(c) Extinction}

Extinction angles are only significant if the orientation of the crystal is known, but, in $N$ general terms, calcium oxalate may display parallel, symmetrical or indeterminate extinction (Peterson $\mathbb{N}$ and Kuhn, 1965).

\section{(d) Refractive index}

Calcium oxalate has three refractive indices due to $\frac{\complement}{\Phi}$ its biaxial form. The most frequent orientation in $\stackrel{?}{+}$ histological material presents the two lower indices, 0 $a=1.490$ and $\beta=1.555$. The proximity of these to the refractive indices of most common mounting 
media accounts for the frequent poor visibility of calcium oxalate in ordinary light microscopy. Other crystals, orientated to show the higher refractive index, $\gamma=1.650$, will be more readily visible in white light (Peterson and Kuhn, 1965). The refractive index of properly orientated crystals may be determined with some accuracy by immersing the section in mounting media and liquids of known refractive index until correspondence is indicated by the Becke line phenomenon (Hartshorne and Stuart, 1970).

\section{SOLUBILITY}

The differential solubility of calcium oxalate is such that it may be distinguished from other histologically occurring calcium salts, such as apatites and pyrophosphates, on this basis alone (Chaplin, 1976b). It is insoluble in water, alkalis, alcohol, and other organic solvents, poorly soluble in periodic acid, and markedly soluble in mineral acids (Yasue, 1969a; Evans et al., 1973; Chaplin, 1974). It is its insolubility in acetic acid which distinguishes calcium oxalate from other calcium salts and forms the basis of its histological identification. Application of the other reagents mentioned should distinguish calcium oxalate from xanthines, urates, cystine, and most other birefringent crystals which may be found in tissue (Wolman, 1975).

\section{MICROINCINERATION}

One of the earliest histochemical practices, microincineration, has been used by many workers in the study of both calcium and its oxalate in sections. The standard technique (Glick, 1949) utilises alcohol or formalin fixed paraffin embedded material cut serially so that alternate sections are used for incineration and for conventional histological examination and topographical comparison with the ashed section. Sections are placed horizontally in a standard muffle furnace and the temperature is gradually raised to $650^{\circ} \mathrm{C}$. To minimise the danger of the slides cracking, they must be allowed to cool slowly. The ashed section, or spodogram, is carefully coverslipped and examined by transmitted light, dark ground illumination, and polarised light. The calcium ash is white and singly refractile, almost insoluble in water, and gives positive gypsum and oxalate tests (Lillie, 1965).

Johnson (1956) demonstrated that controlled incineration at $425-475^{\circ} \mathrm{C}$ converted calcium oxalate to calcium carbonate. This will dissolve with the evolution of bubbles of carbon dioxide if dilute acid is gently applied to the ash. Incineration at $600^{\circ} \mathrm{C}$ yields calcium oxide and no gas is produced on addition of acid. Alternatively, the ash may be carefully stained with alizarin red S (Johnson, 1958) or by the von Kossa method (Wolman and Goldring, 1962).

A simplified incineration procedure, using a fiveminute exposure of the slides to a Meker type Bunsen burner, makes quite usable preparations possible in laboratories where the more elaborate equipment is not available (Johnson and Pani, 1962). Careful comparison of untreated and incinerated sections with regard to acid solubility, evolution of gas, and tinctorial properties again allows in situ identification of calcium oxalate.

Despite its relative simplicity, however, microincineration has certain inherent practical limitations. The ash is easily displaced, even by normal air currents, and this, in a technique which relies heavily on topographical comparison with stained sections, is a serious disadvantage if precise localisation is needed. Its chief value is to provide confirmation of other histochemical findings, and in this respect it remains a useful technique, as several workers have shown (Fanger and Esparza, 1964; Aufderheide, 1971; Bullock et al., 1974; and others).

\section{TINCTORIAL PROPERTIES}

Many of the traditional staining methods for demonstrating sites of calcium have met with only limited success when applied to calcium oxalate. The von Kossa silver nitrate procedure, which demonstrates various anions such as phosphate rather than cations such as calcium, has failed to demonstrate calcium oxalate with any consistency (Chaplin and Grace, 1975). It has been suggested that this is to be expected in view of the low solubility of this salt (Lillie, 1965) and that reactivity may be due to the catalytic activity of any unknown matrix or to co-existence of phosphate or carbonate (Pizzolato, 1964). However, it has been shown that pure calcium oxalate in artificial systems gives positive results with this procedure but displays a lower threshold of positivity and a slower rate of reaction (Chaplin and Grace, 1975). Crystals reacting poorly by the standard one-stage reaction may be consistently stained by exposing the section to bright light after treatment with silver nitrate (McGee-Russell, 1958; Yasue, 1969a; Kurrein et al., 1975).

Difficulties with the von Kossa method led to the development of Pizzolato's hydrogen peroxidesilver nitrate procedure (1964) which theoretically depends on the in situ oxidation of calcium oxalate to calcium carbonate by the hydrogen peroxide, and simultaneous exposure to silver nitrate in bright light. Other workers have failed to reproduce consistent results with this technique (Yasue, 1969a; Kurrein et al., 1975) and it has been suggested that the peroxide merely enhances the weak inter- 
reaction of silver nitrate and calcium oxalate (Yasue, 1969a). It is interesting to note that Macaluso and Berg (1959) described 'no modification' of oxalates by hydrogen peroxide in their studies on the solubility of calcium oxalate.

The silver nitrate-rubeanic acid method described by Yasue (1969a) has proved to be a reliable procedure and is regarded as histologically selective for calcium oxalate when used after acetic acid treatment to remove any possible phosphate or carbonate contamination (Chaplin, 1974). It has given consistent positive results, regardless of illuminating conditions, with material which is shown to be calcium oxalate by other techniques but which gives equivocal staining reactions with other methods (Chaplin, 1974; Jensen, 1975; Kurrein et al., 1975).

A recent study of metal substitution by various tissue components led to the development of a mercurous nitrate procedure for calcium salts, a technique which gives particularly good visualisation of calcium oxalate (Pizzolato and Lillie, 1968; Pizzolato, 1971).

Most of the complexing methods used in the past to demonstrate calcium are unsatisfactory when applied to calcium oxalate. Alkaline quinalizarin (McGee-Russell, 1958) and alizarin red S (Kurrein et al., 1975) have given clear-cut positive staining, but other anthraquinone type dyes generally stain calcium oxalate only peripherally or not at all (Yasue, 1969a; Meloan et al., 1972; Chaplin, 1974). Of more recently introduced complexing methods for calcium, only chloranilic acid and naphthalhydroxamic acid at $\mathrm{pH} 8.5$ proved capable of visualising known oxalate deposits (Voigt, 1957; Chaplin and Grace, 1976). Using naphthalhydroxamic acid on material from a case of ethylene glycol intoxication, Roscher (1971) obtained positive staining in hepatic nuclei, as well as in renal tubules and meninges, providing histological correlation of the biochemically elevated hepatic oxalate levels found in similar cases by Zarembski and Hodgkinson (1967). They suggested that oxalic acid may be deposited as a non-crystalline complex of calcium oxalate and lipid in the liver in such cases. It is possible that such organic deposits are unreactive to other tinctorial techniques due to their unusual chemical combination.

I should like to thank Professor J. O'D. McGee, in whose department the practical aspects of this study were carried out, Dr M. S. Dunnill for his advice and criticism, Mr T. Reed for the photomicrographs, and Mrs R. Hunt for the typescript. Dr R. D. Lewis, of the Huntingdon Memorial Hospital, Pasadena, provided the myocardial tissue used for Figure 2.

\section{References}

Allen, A. C. (1962). The Kidney, 2nd edition. Grune and Stratton, New York.

Allen, A. C. (1976). Acute lobular (membranoproliferative) glomerulonephritis with hyperuricemia and obstructive uric acid nephropathy. American Journal of Clinical Pathology, 65, 109-120.

Arbus, G. S., and Sniderman, S. (1974). Oxalosis with peripheral gangrene. Archives of Pathology, 97, 107-110.

Archer, H. E., Dormer, A. E., Scowen, E. F., and Watts, R. W. E. (1958). The aetiology of primary hyperoxaluria. British Medical Journal, 1, 175-181.

Aufderheide, A. C. (1971). Renal tubular calcium oxalate crystal deposition. Archives of Pathology, 92, 162-166.

Bennett, B., and Rosenblum, C. (1961). Identification of calcium oxalate crystals in the myocardium of patients with uraemia. Laboratory Investigation, 10, 947-955.

Bennington, J. L., Haber, S. L., Smith, J. V., and Warner, N. E. (1964). Crystals of calcium oxalate in the human kidney. American Journal of Clinical Pathology, 41, 8-14.

Beppu, T., Mori, S., Omoto, R., Nishi, T., and Oya, G. (1975). Secondary oxalosis after ileocaecal resection. Japanese Journal of Gastroenterology, 72, 520-526.

Bergstrand, A., Collste, L. G., Franksson, C., Glass, J. E., Löfström, B., Magnusson, G., Nordenstam, H., and Werner, B. (1972). Oxalosis in renal transplants following methoxyflurane anaesthesia. British Journof of Anaesthesia, 44, 569-574.

Bisaillon, S., and Tawashi, R. (1975). Growth of calcium oxalate in gel systems. Journal of Pharmaceuticat Sciences, 64, 458-460.

Boquist, L., Lindqvist, B., Östberg, Y., and Steen, L. (1973). Primary oxalosis. American Journal of Medicine, $54,673-681$.

Bourke, E., and Costello, J. (1975). The clinical importance of oxalic acid. Journal of the Irish Medical Association, 68, 93-96.

Bove, K. E. (1966). Ethylene glycol toxicity. American Journal of Clinical Pathology, 45, 46-50.

Briggs, M. (1976). Vitamin-C-induced hyperoxaluria (Letter). Lancet, 1 (7951), 154.

Bullock, J. D., Albert, D. M., Skinner, C. W., Miller, W. H., and Galla, J. H. (1974). Calcium oxalate retinopathy associated with generalised oxalosis. Investigative Ophthalmology, 13, 256-265.

Chaplin, A. J. (1974). Some observations on the demonstration of calcium oxalate in tissue sections. Stain Technology, 49, 165-173.

Chaplin, A. J. (1976a). Unpublished observations.

Chaplin, A. J. (1976b). Calcium pyrophosphate. Histological characterisation of crystals in pseudogout. Archives of Pathology and Laboratory Medicine, 100, $\mathrm{\omega}$ 12-15.

Chaplin, A. J., and Grace, S. R. (1975). Calcium oxalate and the von Kossa method with reference to the $\frac{D}{D}$ influence of citric acid. Histochemical Journal, 7, 451- ? 458.

Chaplin, A. J., and Grace, S. R. (1976). An evaluation of $\frac{7}{0}$ some complexing methods for the histochemistry of $\overrightarrow{\mathbb{D}}$ calcium. Histochemistry, 47, 263-269. 
Cochran, M., Hodgkinson, A., Zarembski, P. M., and Anderson, C. K. (1968). Hyperoxaluria in adults. British Journal of Surgery, 55, 121-128.

Cogan, D. G., Kuwabara, T., Silbert, J., Kern, H., McMurray, V., and Hurlbut, C. (1958). Calcium oxalate and calcium phosphate crystals in detached retinas. Archives of Ophthalmology, 60, 366-371.

Coltart, D. J., and Hudson, R. E. B. (1971). Primary oxalosis of the heart: a cause of heart block. British Heart Journal, 33, 315-319.

Cotton, J. R., Jr., Schwartz, M. M., Lindley, J. D., and Hunsicker, L. G. (1976). Acute renal failure following Halothane anesthesia. Archives of Pathology and Laboratory Medicine, 100, 628-629.

Crampton, R. F., and Charlesworth, F. A. (1975). Occurrence of natural toxins in food. British Medical Bulletin, 31, 209-213.

Cryer, P. E., Garber, A. J., Hoffsten, P., Lucas, B., and Wise, L. (1975). Renal failure after small intestinal bypass for obesity. Archives of Internal Medicine, 135, 1610-1612.

Daniels, R. A., Michels, R., Aisen, P., and Goldstein, G. (1960). Familial hyperoxaluria. American Journal of Medicine, 29, 820-831.

Dempsey, E. F., Forbes, A. P., Melick, R. A., and Henneman, P. H. (1960). Urinary oxalate excretion. Metabolism, 9, 52-58.

Deodhar, S. D., Tung, K. S. K., Zühlke, V., and Nakamoto, S. (1969). Renal homotransplantation in a patient with primary familial oxalosis. Archives of Pathology, 87, 118-124.

Dowling, R. H., Rose, G. A., and Sutor, D. J. (1971). Hyperoxaluria and renal calculi in ileal disease. Lancet, 1, 1103-1106.

Doyle, W. F., Brahman, H. D., and Burgess, J. H. (1973). The nature of yellow-brown bodies in peritoneal lymph nodes. Archives of Pathology, 96, 320-326.

Dunn, J. S., Haworth, A., and Jones, N. A. (1924). The pathology of oxalate nephritis. Journal of Pathology and Bacteriology, 27, 299-318.

Dyke, P. C., Hajdu, S. I., Strong, E. W., Erlandson, R. A., and Fleisher, M. (1971). Mixed tumour of parotid containing calcium oxalate crystals. Archives of Pathology, 91, 89-92.

Earnest, D. L., Johnson, G., Williams, H. E., and Admirand, W. H. (1974). Hyperoxaluria in patients with ileal resection: an abnormality in dietary oxalate absorption. Gastroenterology, 66, 1114-1122.

Evans, G. W., Phillips, G., Mukherjee, T. M., Snow, M. R., Lawrence, J. R., and Thomas, D. W. (1973). Identification of crystals deposited in brain and kidney after xylitol administration by biochemical, histochemical, and electron diffraction methods. Journal of Clinical Pathology, 26, 32-36.

Faber, S. R., Feitler, W. W., Bleiler, R. E., Ohlson, M. A., and Hodges, R. E. (1963). The effects of an induced pyridoxine and pantothenic acid deficiency on excretions of oxalic and xanthurenic acids in the urine. American Journal of Clinical Nutrition, 12, 406-412.

Fanger, H., and Esparza, A. (1964). Crystals of calcium oxalate in kidneys in uremia. American Journal of Clinical Pathology, 41, 597-603.
Flocks, M., Littwin, C. S., and Zimmerman, L. E. (1955). Phacolytic glaucoma. A clinco-pathologic study of one hundred and thirty-eight cases of glaucoma associated with hypermature cataract. Archives of Ophthalmology, 54, 37-45.

Franco, V., and Krinitz, B. (1973). Determination of oxalic acid in foods. Journal of the Association of Official Analytical Chemists, 56, 164-166.

Friedman, A. H., and Charles, N. C. (1974). Retinal oxalosis in two diabetic patients. American Journal of Ophthalmology, 78, 189-195.

Friedman, E. A., Greenberg, J. B., Merrill, J. P., and Dammin, G. J. (1962). Consequences of ethylene glycol poisoning. American Journal of Medicine, 32, 891-902.

Garner, A. (1974). Retinal oxalosis. British Journal of Ophthalmology, 58, 613-619.

Geiling, E. M. K., and Cannon, P. R. (1938). Pathologic effects of elixir of sulfanilamide (diethylene glycol) poisoning; clinical and experimental correlation: final report. Journal of the American Medical Association, 111, 919-926.

Gelfand, S. G., and Taranto, A. I. (1973). Hyperoxaluria and Meckel's Diverticulum (Letter). Annals of Internal Medicine, 79, 748-749.

Gershoff, S. N., Faragalla, F. F., Nelson, D. A., and Andrus, S. B. (1959). Vitamin $B_{6}$ deficiency and oxalate nephrocalcinosis in the cat. American Journal of Medicine, 27, 72-80.

Gessner, P. K., Parke, D. V., and Williams, R. T. (1961). Studies in detoxication 86 . The metabolism of ${ }^{14} \mathrm{C}$ labelled ethylene glycol. Biochemical Journal, 79, 482-489.

Glick, D. (1949). Techniques of Histo- and Cytochemistry. Interscience, New York.

Glynn, L. E. (1940). Crystalline bodies in the tunica media of a middle cerebral artery. Journal of Pathology and Bacteriology, 51, 445-446.

Gross, S. (1955). Granulomatous thyroiditis with anisotropic crystalline material. Archives of Pathology, 59, 412-418.

Harris, A. B. (1976). Vitamin-C-induced hyperoxaluria (Letter). Lancet, 1, 366.

Hartshorne, N. H., and Stuart, A. (1970). Crystals and the Polarising Microscope, 4th edition. Arnold, London.

Hauschildt, S., Chalmers, R. A., Lawson, A. M., Schultis, K., and Watts, R. W. E. (1976). Metabolic investigations after xylitol infusion in human subjects. American Journal of Clinical Nutrition, 29, 258-273.

Hauschildt, S., and Watts, R. W. E. (1976). Studies on the effect of xylitol on oxalate formation. Biochemical Pharmacology, 25, 27-29.

Hockaday, T. D. R., Clayton, J. E., Frederick, E. W., and Smith, L. H., Jr. (1964). Primary hyperoxaluria. Medicine, 43, 315-345.

Hodgkinson, A., and Zarembski, P. M. (1968). Oxalic acid metabolism in man: a review. Calcified Tissue Research, 2, 115-132.

Hughes, D. T. D. (1959). The clinical and pathological background on two cases of oxalosis. Journal of Clinical Pathology, 12, 498-509.

James, L. F. (1972). Oxalate toxicosis. Clinical Toxi- 
cology, 5, 231-243.

Jansen, L. H., Groeneveld, J. L., and van der Meer, J. B. (1974). Deposition of calcium oxalate in the skin in two patients suffering from oxalosis caused by primary hyperoxaluria. Archiv für Dermatologische Forschung, 250, 323-350.

Jeghers, H., and Murphy, R. (1945). Practical aspects of oxalate metabolism. New England Journal of Medicine, 233, 208-215.

Jensen, O. A. (1975). Calcium oxalate crystals localised in the eye. Acta Ophthalmologica, 53, 187-196.

Johnson, F. B. (1956). A method for demonstrating calcium oxalate in tissue sections (Abstract). Journal of Histochemistry and Cytochemistry, 4, 404-405.

Johnson, F. B. (1958). Further observations on the identification of calcium oxalate in tissue sections (Abstract). Journal of Histochemistry and Cytochemistry, 6, 405.

Johnson, F. B., and Pani, K. (1962). Histochemical identification of calcium oxalate. Archives of Pathology, 74, 347-351.

Kinnett, J. G., and Bullough, P. G. (1976). Identification of calcium oxalate deposits in bone by electron diffraction. Archives of Pathology and Laboratory Medicine, 100, 656-658.

Klauwers, J., Wolf, P. L., and Cohn, R. (1969). Failure of renal transplantation in primary oxalosis. Journal of the American Medical Association, 209, 551.

Kobert, R., and Küssner, B. (1879). Die experimentellen Wirkungen der Oxalsäure. Virchows Archiv für pathologische Anatomie und Physiologie, 78, 209-244.

Koten, J. W., van Gastel, C., Dorhout Mees, E. J., Holleman, L. W. J., and Schuiling, R. D. (1965). Two cases of primary oxalosis. Journal of Clinical Pathology, 18, 223-229.

Kurrein, F., Green, G. H., and Rowles, S. L. (1975). Localised deposition of calcium oxalate around a pulmonary Aspergillus niger fungus ball. American Journal of Clinical Pathology, 64, 556-563.

Kuzucu, E. Y. (1970). Methoxyflurane, tetracycline, and renal failure. Journal of the American Medical Association, 211, 1162-1164.

Lewis, R. D., Lowenstam, H. A., and Rossman, G. R. (1974). Oxalate nephrosis and cystalline myocarditis. Archives of Pathology, 98, 149-155.

Lillie, R. D. (1965). Histopathological Technic and Practical Histochemistry, 3rd edition. McGraw-Hill, New York.

Lindholm, J. (1965). Intra-vitam diagnosis of oxalosis. Acta Medica Scandinavica, 178, 155-159.

Macaluso, M. P., and Berg, N. O. (1959). Calcium oxalate crystals in kidneys in acute tubular nephrosis and other renal diseases with functional failure. Acta Pathologica Microbiologica Scandinavica, 46, 197-205.

McCollum, J. P. K., Packer, S., Manning, J., and Harries, J. T. (1974). Hyperoxaluria in children with hepatic and intestinal dysfunction (Abstract). Archives of Diseases in Childhood, 49, 749.

McGee-Russell, S. M. (1958). Histochemical methods for calcium. Journal of Histochemistry and Cytochemistry, 6, 22-42.

Mazze, R. I., Trudell, J. R., and Cousins, M. J. (1971).
Methoxyflurane metabolism and renal dysfunction: $\stackrel{0}{\vec{*}}$ clinical correlation in man. Anesthesiology, 35, 247-252.

Meloan, S. N., Puchtler, H., and Valentine, L. S. (1972). Alkaline and acid alizarin red $\mathbf{S}$ stains. Archives of Pathology, 93, 190-197.

Milgram, J. W., and Salyer, W. R. (1974). Secondary oxalosis of bone in chronic renal failure. Journal of Bone and Joint Surgery, 56A, 387-395.

Mohr, W., and Hey, D. (1969). Endogene Oxalose mit Manifestation im Erwachsenenalter. Virchows Archiv की Abt A, Pathologische Anatomie, 347, 185-196.

Nime, F. A., and Hutchins, G. M. (1973). Oxalosis caused by Aspergillus infection. Johns Hopkins Medical Journal, 133, 183-194.

Peterson, B. J., and Kuhn, R. J. (1965). Optical characteristics of crystals in tissue. Cystine and calcium oxalate monohydrate. American Journal of Clinical Pathology, 43, 401-408.

Pizzolato, P. (1964). Histochemical recognition of calcium oxalate. Journal of Histochemistry and Cytochemistry, 12, 333-336.

Pizzolato, P. (1971). Mercurous nitrate as a histochemical reagent for calcium phosphate in bone and pathological calcification and for calcium oxalate. Histochemical Journal, 3, 463-469.

Pizzolato, P., and Lillie, R. D. (1968). The impregnation of bone and pathologic calcification by metal salts and their recognition by unoxidised haematoxylin. Histo chemie, 16, 333-338.

Pons, C. A., and Custer, R. P. (1946). Acute ethylen glycol poisoning: a clinico-pathologic report o eighteen fatal cases. American Journal of Medic $\overrightarrow{a t}$ Science, 211, 544-552.

Raper, K. B., and Fennell, D. I. (1965). The Genus Aspergillus. Williams and Wilkins, Baltimore.

Richter, M. N. (1940). Anisotropic crystalloids in the human thyroid gland (Abstract). American Journal of Pathology, 16, 654-655.

Richter, M. N., and McCarty, K. S. (1954). Anisotropic crystals in the human thyroid gland. American Journal of Pathology, 30, 545-552.

Roscher, A. A. (1971). A new histochemical method for the demonstration of calcium oxalate in tissues following ethylene glycol poisoning. American Journal of Clinical Pathology, 55, 99-104.

Roughan, P. G., and Slack, C. R. (1973). Simple methods for routine screening and quantitative estimation of $\mathrm{O}$ oxalate content of tropical grasses. Journal of the Science of Food and Agriculture, 24, 803-811.

Salyer, W. R., and Hutchins, G. M. (1974). Cardiac lesions in secondary oxalosis. Archives of Internal N Medicine, 134, 250-252.

Salyer, W. R., and Keren, D. (1973). Oxalosis as a $\mathcal{O}^{2}$ complication of chronic renal failure. Kidney Inter- $\mathrm{W}$ national, 4, 61-66.

Salyer, W. R., and Salyer, D. C. (1974). Thiamine deficiency and oxalosis. Journal of Clinical Pathology, 27, 558-559.

Sanderson-Damberg, E. Die(1910). Schildrüsen vom 15-25 Lebensjahr aus der norddeutschen Ebene und Küstengegend, sowie aus Bern. Frankfurter Zeitschrift für $\underset{\mathbb{D}}{\mathrm{D}}$ Pathologie, 6, 312-334. Cited by Richter and McCarty 
(1954).

Saunders, D. R., Sillery, J., and McDonald, G. B. (1975). Regional differences in oxalate absorption by rat intestine: evidence for excessive absorption by the colon in steatorrhoea. Gut, 16, 543-554.

Schröder, R., De Lacroix, W. F., and Franzen, U., et al. (1974). Therapie-bedingte Form einer reno-cerebralen Oxalose. Acta Neuropathologica (Berlin), 27, 181-184

Scowen, E. F., Stansfeld, A. G., and Watts, R. W. E. (1959). Oxalosis and primary hyperoxaluria. Journal of Pathology and Bacteriology, 77, 195-205.

Smith, L. H., Jr. (1968). Symposium on stones. Introduction. American Journal of Medicine, 45, 649-653.

Stauffer, M. (1960). Oxalosis. Report of a case, with a review of the literature and discussion of the pathogenesis. New England Journal of Medicine, 263, 386-390.

Sutor, D. J. (1969). Growth studies of calcium oxalate in the presence of various ions and compounds. British Journal of Urology, 41, 171-178.

Tallqvist, H., and Väänänen, I. (1960). Death of a child from oxalic acid poisoning due to eating rhubarb leaves. Annales Paediatriae Fenniae, 6, 144-147.

Thomas, D. W., Edwards, J. B., Gilligan, J. E., Lawrence, J. R., and Edwards, R. G. (1972). Complications following intravenous administration of solution containing xylitol. Medical Journal of Australia, 1, 1238-1246.

Vainder, M., and Kelly, J. (1976). Renal tubular dysfunction secondary to jejunoileal bypass. Journal of the American Medical Association, 235, 1257-1258.

Valman, H. B., Oberholzer, V. G., and Palmer, T. (1974). Hyperoxaluria after resection of ileum in children. Archives of Diseases in Childhood, 49, 171-173.

Vermeulen, C. W., and Lyon, E. S. (1968). Mechanisms of genesis and growth of calculi. American Journal of Medicine, 45, 684-692.

Voigt, G. E. (1957). Der histochemische Nachweis des
Calciums im Calciumoxalate bei der Äthylenglykolvergiftung. Acta Pathologica Microbiologica Scandinavica, 41, 89-95.

Watts, R. W. E. (1973). Oxaluria. Journal of the Royal College of Physicians of London, 7, 161-174.

Williams, H. E., and Smith, L. H., Jr. (1968). Disorders of oxalate metabolism. American Journal of Medicine, 45, 715-735.

Williams, H. E., and Smith, L. H., Jr. (1972). Primary hyperoxaluria. In The Metabolic Basis of Inherited Diseases, 3rd edition, edited by 'J. B. Stanbury, J. B. Wyngaarden, and D. S. Frederickson, pp. 196-219. McGraw-Hill Book Company, New York.

Wolman, M. (1975). Polarised light microscopy as a tool of diagnostic pathology. Journal of Histochemistry and Cytochemistry, 23, 21-50.

Wolman, M., and Goldring, D. (1962). Histochemical demonstration of calcium oxalate crystals. Journal of Histochemistry and Cytochemistry, 10, 505-506.

Yasue, T. (1969a). Histochemical identification of calcium oxalate. Acta Histochemica et Cytochemica, 2, 83-95.

Yasue, T. (1969b). Renal crystalline deposition and its pathogenesis. Acta Histochemica et Cytochemica, 2, 96-111.

Zarembski, P. M., and Hodgkinson, A. (1967). Plasma oxalic acid and calcium levels in oxalate poisoning. Journal of Clinical Pathology, 20, 283-285.

Zarembski, P. M., Hodgkinson, A., and Parsons, F. M. (1966). Elevation of the concentration of plasma oxalic acid in renal failure. Nature, 212, 511-512.

Zeiss, O. (1877). Mikroskopische Untersuchungen über den Bau der Schilddrüse. Inaugural dissertation, Strassburg. Cited by Richter and McCarty (1954).

Zimmerman, L. E., and Johnson, F. B. (1958). Calcium oxalate crystals within ocular tissues. Archives of Ophthalmology, 60, 372-383. 